\title{
LA NOCHE DE LOS PROLETARIOS DE JACQUES RANCIÈRE COMO POSIBILIDAD PARA PENSAR EN OTRO TIPO DE COMUNIDAD
}

\author{
Diana Milena Patiño Niño* \\ doi:10.11144/Javeriana.uph34-68.npjr
}

\begin{abstract}
RESUMEN
El presente escrito tiene por objetivo mostrar que La noche de los proletarios de Jacques Rancière proporciona elementos para pensar un tipo de comunidad diferente a aquellas que se afirman a partir de la negación, o aquellas que se conciben a partir de la dialéctica de inclusión y exclusión, que define un adentro y un afuera de lo colectivo, un propio y un impropio. En este sentido, creemos que a través de la mencionada obra aflora una inquietud por la comunidad de una forma bastante desplazada a como habitualmente la pensamos, toda vez que más que de comunidad, Rancière habla de una experiencia comunitaria que hace referencia a una cierta inquietud que abre posibilidades de alteración o de transformaciones singulares y del ser-en-común.

Palabras clave: Jacques Rancière; comunidad; La noche de los proletarios; Louis-Gabriel Gauny
\end{abstract}

Universidad de La Sabana, Chía, Colombia.

Correo electrónico: dianapani@unisabana.edu.co

Para citar este artículo: Patiño Niño, D.M. (2017). La noche de los proletarios de Jacques Rancière como posibilidad para pensar en otro tipo de comunidad. Universitas Philosophica 34(68), pp. 243-262. ISSN 0120-5323, ISSN en línea 2346-2426. doi:10.11144/Javeriana.uph34-68.npjr

Producto adscrito al grupo de investigación Rancionalidad y Cultura de la Universidad de La Sabana. 


\title{
THE POSSIBILITY OF ANOTHER KIND OF COMMUNITY IN JACQUES RANCIÈRE'S THE NIGHTS OF LABOR
}

\author{
Diana Milena Patiño Niño
}

\begin{abstract}
The primary focus of this work is to show that it is possible to find a certain way to think the community, a very different kind of community to those ways of conceiving the community from a certain dialectic of inclusion and exclusion, defining an inside and an outside of the collective, a proper and improper. In that sense, we believe that through the aforementioned work emerges a concern for the community but in a rather shifted from how we usually think this. When we think about a community experience through The Nights of Labor we refer to a certain attitude that opens possibilities of change and possibilities of being-in-common.
\end{abstract}

Key words: Jacques Rancière; community; The Nights of Labor; LouisGabriel Gauny 


\section{Introducción}

EN LA ENTREVISTA CONCEDIDA a Laurent Jeanpierre y Dork Zabuyan (2012), Rancière relata que hacia 1972 se embarcó en una aventura intelectual que años atrás había iniciado con la separación de su maestro Louis Althusser: desencantado y distanciado del marxismo althusseriano; convencido de la existencia de una brecha entre el marxismo que había aprendido y enseñado y la realidad del mundo obrero; y persuadido de la existencia de una verdadera clase obrera, Rancière emprendió una búsqueda en el archivo obrero francés del siglo XIX. Sin embargo, el azar decidió de otra manera, pues el material con el que se encontró no constituía el reflejo de unas verdades obreras; en lugar de eso, a través de folletos, periódicos y diferentes archivos (Archivos Nacionales, Fondo Sansimoniano del Arsenal, Fondo Gauny de Saint-Denis, entre otros), Rancière pudo percibir cómo emergían las figuras de unos proletarios que desajustaban aquello que había sido considerado característico de su identidad ${ }^{1}$ y de su cultura: poetas-carpinteros, zapateros-poetas, costureras-poetas; figuras que aparecían habitando un espacio intermedio y de libertad entre su ser obrero y su ser artista, poeta o escritor; figuras escondidas, suspendidas en el tiempo por los retratos en sepia que la nostalgia de un ser obrero llevaba a configurar.

Estos hallazgos llevaron a Rancière por caminos inesperados que, como la experiencia kantiana de lo bello, hicieron emerger un libre juego de las facultades, dando vida a una nueva forma de pensar a partir de una nueva forma de escribir en La noche de los proletarios. Efectivamente, y como él mismo lo reconoce, el material ${ }^{2}$ con el que se encontró le impuso el nacimiento de una forma de

1 La imposibilidad de encontrar en esos relatos la identidad obrera, descubre Rancière, no era consecuencia de que sus autores fueran unos obreros enceguecidos, anhelosos de la vida burguesa, que no hacían más que reproducir "el pensamiento establecido que es el mismo que está hecho para enceguecerlos y para impedirles el camino de su liberación” (Rancière , 2010, p. 40). Por el contrario, aquellos obreros sabían dirigirse contra aquello que se aprestaba a devorarlos, es decir, sabían y conocían su situación, pero no para afirmar una identidad obrera que les habría sido asignada, sino para fugarse de ella, habitando más bien en un intervalo entre identidades (identidades intermedias).

$2 \mathrm{Al}$ respecto Rancière (2010) señala: "Esta escritura me fue impuesta por mi material, que estaba mayoritariamente conformado por textos obreros que constituían ellos mismos un acontecimiento: la entrada en la escritura de personas que se suponía que vivían en el mundo "popular" de la oralidad. Yo tenía que dar cuenta de este acontecimiento y hacer sentir la vibración poética de sus textos y del contenido de sus pensamientos" (p. 7). 
escritura que fue y aún es considerada como una cierta lengua extranjera, tanto para la historia como para la filosofía; disciplinas que en su momento negaron tener parte en ese trabajo ${ }^{3}$, pese a que en cierta forma eran investigaciones sobre historia y filosofía.

La falta de identidad o de estilo narrativo definido de La noche de los proletarios -que incluso podríamos percibir con rasgos babilónicos- no es percibida solamente por esas academias que muchas veces descubrimos como estáticas y cuidadosamente amojonadas, sino también por muchos de sus lectores que quedamos impedidos al intentar clasificar este tipo de escritura dentro de las categorías convencionales de la filosofía o la historiografía. Es justamente por esto que el Colectivo Situaciones en la entrevista que introduce la versión en español de La noche de los proletarios, afirma que esta forma peculiar de escritura "supone una invitación a la lectura no convencional y exige del lector, [...] más que un interés determinado cierta curiosidad libre" (Rancière, 2010, p. 7). En nuestro caso, el despliegue de aquella curiosidad libre suscitó una cierta perplejidad y un libre juego de las facultades que nos permitió pensar de otra forma lo que se conoce como comunidad, a saber, agruapaciones o colecciones de individuos, un cuerpo colectivo, un nosotros que tiende a sustancializarse a partir de la creación de una identidad cerrada. La comunidad, en este sentido, funciona bajo una dialéctica de exclusión e inclusión; nociones que ciertamente podemos descubrir en los cimientos de muchos y variados movimientos: tanto de aquellos que demandan derechos o reconocimiento a diversos Estados u otro tipo de organizaciones gubernamentales ${ }^{4}$, como de aquellos del pasado y del presente que, en múltiples niveles, niegan las existencias de otros 5 .

3 "Era un ovni que finalmente no fue aceptado por alguna corporación en tanto tal" (Rancière, 2012, p. 51).

4 Movimientos tales como la NAACP que desde 1909 "comenzó lo que se ha convertido en su legado de luchar batallas legales para ganar la justicia social para los afroamericanos y, de hecho, para todos los estadounidenses [...] y hoy en día, los abogados NAACP siguen asumiendo el reto de la discriminación racial ya sea que aparezca en la apariencia de las condiciones corporativas que discriminan a los estudiantes universitarios afroamericanos, en la privación de derechos de voto durante las elecciones presidenciales nacionales, o en símbolos patrocinados por el estado de la supremacía blanca, como la bandera de batalla confederada" (NAACP, 2009-2016).

5 Discursos tales como el de Estado Islámico cuyo objetivo es la creación de un califato erradicando "los obstáculos para restaurar el reinado de Dios en la Tierra y para defender la comunidad mu- 
En efecto, la narración desplegada en la obra acá tratada, específicamente, aquella efectuada por el proletario (carpintero-poeta) Louis-Gabriel Gauny, permite atender a experiencias de apertura y alteraciones singulares, de circulación, de difusión, de redes de relaciones, de puentes con otros, que son, ciertamente, experiencias de comunidad. Experiencias que emergían justamente de acoger la inquietud por el ser-en-común que estaban tensa y polémicamente vinculadas, o incluso en directa confrontación, con formas de comunidad que, según se lee en La noche de los proletarios, proliferaron a lo largo del siglo XIX en París. Estas promulgaban un mundo enteramente nuevo que dejara atrás al viejo trabajador, condenado a las libaciones de la inferioridad su raza ${ }^{6}$ y a la repetición del círculo de la dominación a la que lo subyugaba otra clase y sus mismos apetitos. Inquietud que parecería estar relacionada, más que con la continuidad de los cuerpos, con la distancia: con la posibilidad, paradójicamente, de abrir ciertas distancias en y entre los cuerpos.

Así pues, con el objetivo de recoger y hacer sonar de nuevo aquella inusual experiencia del proletario francés, en lo que sigue examinaremos cuidadosamente aquellas escenas a través de las cuales hemos visto movilizar de una forma divergente la mencionada inquietud por el ser-en-común. Creemos sin duda que este tipo de análisis posibilita pensar desplazamientos y quiebres en las nociones sustantivas de comunidad que pueden tener efectos sobre la vida, y que no necesariamente se plantean a sí mismos como discursos de la verdad sobre la comunidad sino como alternativas posibles. Al finalizar expondremos algunas consideraciones respecto de la obra de Rancière en relación con los hallazgos acá presentados.

sulmana, o umma, contra los infieles y apóstatas" (traducción propia, BBC, 2015), o como el del movimiento PEGIDA por sus siglas en alemán de europeos patriotas contra la islamización de occidente cuyo objetivo es evitar la islamización de occidente (DW, 2016).

6 Se habla de raza retomando los términos movilizados en la narración rancieriana y que en cierta forma ponen de presente nociones incorporadas en la cultura de la época, en donde se separaba a los proletarios de las otras formas de ser humano. Al respecto Rancière afirma: "el mundo de los trabajadores [...] debe ser pensado menos como una clase de la sociedad que como una raza de la humanidad" (Rancière, 2010, p. 172). 
GAUNY APARECE A TRAVÉs de La noche de los proletarios como una suerte de adherente al sansimonismo, como religión o proyecto utópico cuyo interés primordial parece reposar en la comunidad, esto es, en propiciar y más aún producir cierto tipo de comunidad. Sin embargo, si nos guiamos por algunas declaraciones de Gauny respecto de ese tipo de comunidad, nuestro carpintero aparece como un adherente bastante irregular. Visitado varias veces por el predicador Delaporte, con quien no tendrá una buena relación; frecuentado por el predicador y reclutador sansimoniano Bergier, con quien establece una viva correspondencia durante varios años (Rancière, 2010, pp. 46, 155); amigo de, como narra Rancière (1983), “uno de los predicadores más elocuentes de la doctrina” (p. 9), Moïse Retouret; nuestro poeta-carpintero hará parte del círculo sansimoniano durante algunos años y, bajo la protección de Enfantin -padre supremo del sansimonismo-, trabajará como guardia en la construcción del ferrocarril de Lyon.

A pesar de hacer parte del círculo sansimoniano, "su relación con el sansimonismo será una extraño juego de adhesión a distancia”: nuestro carpintero será más bien, como el mismo Bergier lo nota en un informe, un "devorador de ideas" (Rancière, 1983, p. 9), es decir, un adherente a algunas ideas que circulan a través de dicha doctrina y no un adherente según las reglas que esa religión ha fijado. Así pues, no hará parte activa de la comunidad sansimoniana conformada por aquellos que, teniendo en común una forma de vida, unas creencias, unos valores y una visión del mundo por venir ${ }^{7}$, se unen en la identidad de una sola familia que comparte la mesa, prédicas e incluso, en algunos casos, el mismo techo.

Esta extraña adherencia, contrario a lo que en un primer momento podríamos pensar, no es fruto de una decisión ni de la rebeldía sin causa de nuestro

7 Dicho mundo por venir, como lo afirman algunos sansimonianos, se formará a partir del abandono de la vieja sociedad que, dejando atrás los vicios de esta -en específico, ese "mal fundamental que la economía llama concurrencia y la moral egoísmo”- (Rancière, 2010, p. 104), abrirá las puertas de ese mundo en el que la dependencia económica a un patrón ya no marcaría el camino de la opresión y de la muerte y donde el universo popular sería recompuesto: "Levantaos en medio de los desgraciados obreros, vuestros amigos, vuestros camaradas, y decidles: Abandonad, abandonad esta sociedad para la que vosotros hacéis todo y que no hace nada por vosotros; esta sociedad donde los que hacen todo no tienen absolutamente nada, donde los que no hacen nada poseen todo [...]. Un mundo nuevo se os ofrece, arrojaos en los brazos de los hombres generosos que vienen a anunciarlo; y pronto seréis felices" (Rancière, 2010, p. 239). 
carpintero-poeta; por el contrario, esta emerge de su deseo por unir la voz a la de sus hermanos del sansimonismo -y de esta forma, seguir los direccionamientos dados por Enfantin-y de la imposibilidad que sufre de "transformar en comunión activa su amor de lejos” (Rancière, 2010, p. 270). Al respecto Gauny afirma:

Dos incoherencias coinciden en mí. Una viene por impulsos eléctricos; es una voluntad viril; una virtud primordial de obrar, de avanzar en la perfección, de amar sin obligación, sin restricción y de aplastar la hidra que me aprisiona; la otra un entrañamiento solitario, sofístico, horrible. Yo veo, amo vuestra armonía y no me veo con armonía, quisiera unir mi voz a las modulaciones de vuestros himnos, mi boca está clavada, no puedo lanzar mi plegaria a las llamas de vuestras plegarias, no puedo orar; un impedimento de pesadilla hace de mi vida un infernal delirio y la idea palpitante de un sueño improbable [...]. Permaneceré fiel a vuestra causa pero apartándome de las alegrías de aquellos que vienen a compartir sus trabajos en los días de reunión. (Rancière, 2010, p. 270)

Además de esta imposibilidad confesada por el mismo Gauny, la adhesión a la distancia, según lo relata Delaporte en el informe que sobre Gauny transmite a Enfantin, parece manar también de una inquietud personal de este carpinteropoeta, a saber, una aspiración al infinito:

Él concibe la moral como un tipo absoluto e invariable, y el hombre como pudiendo apasionarse por ella, por sí misma, por su belleza abstracta y, conminado a precisar el límite planteado por él a la moral, me respondió: la infinita bondad.

Espero haberlo convencido de la inconsecuencia de presentar al infinito como tipo determinado, pues la idea de infinito supone siempre algo más allá de lo que sabemos [...] que para nosotros el amor no puede ser una pura abstracción sino deseo de un objeto determinado; que sin duda sólo amamos los objetos a los cuales nos sentimos ligados, de los cuales sentimos o conocemos lo que se relaciona con nosotros, que nuestra ciencia es progresiva, luego nuestro amor y por consiguiente nuestra moral. (Rancière, 2010, pp. 269-270).

A partir de ahí, podríamos pensar que la cuestión por la comunidad está fuera de la mesa para Gauny: sus deseos, impulsos y anhelos parecen situarlo por fuera de cualquier posibilidad de entablar comunidad, aún junto a aquellos con quienes 
tiene algunas similitudes en lo relativo a ideas. Por eso, él mismo dirá de sí: "el trabajador rebelde, perdido en la inmensa arena de la vida, debe considerarse como un gladiador independiente abandonado por aquellos mismos que comparten su causa. Combate sin pedir ayuda, sin clamar gracia" (Rancière, 2010, p. 160).

A pesar de esa imposibilidad por formar comunidad, una particular experiencia que emerge en su trabajo - poniendo el parquet en una casa-, y de la cual él nos deja registro escrito, nos lleva a pensar que en Gauny parece moverse una cierta inquietud por la apertura a experiencias que tienen efectos en la manera en cómo se-es-con-otros, esto es, con respecto al ser-en-común; inquietud muy diferente a aquellas formas de concebir la comunidad a partir de una cierta dialéctica de inclusión y exclusión, que define un adentro y un afuera de lo colectivo, un propio y un impropio. En ese sentido, estaría presente en él una cierta inquietud por la comunidad pero de una forma bastante desplazada a como habitualmente pensamos este tipo de relación. A continuación retomaremos las palabras del mismo Gauny para describir esa experiencia.

Gauny, trabajando como carpintero a destajo, disfruta de una libertad otra que le proporciona esa labor "en casas donde trabaja a sus horas, sin amo, capataz ni colegas" (Rancière, 2010, p. 114). Libertad ganada gracias a las torsiones que efectúa del tiempo y del espacio:

Este obrero, que la exactitud de la hora no ha sofocado, considera un instante su tarea disponiéndose a proseguir su buen cumplimiento. Sus herramientas no tienen nada que lo desanime, las toca con una suerte de amistad. Abandonándose a las riquezas de su libertad, los lugares de trabajo, el tiempo que debe pasar allí no lo entristece jamás [...] él no teme la mirada abominable del patrón, ni la señal de las horas que fuerza a los otros obreros a romper su charla para correr bajo el yugo [...] [;] afiebrado de acción, las horas giran rápido para él; su tarea que fecunda acelerándola es un magnetismo que, de la mañana al anochecer, domina su pensamiento y hace que devore el tiempo cuando el hombre en la jornada es devorado por él. (Rancière, 2010, p. 116)

La libertad entregada en el mismo tiempo y lugar de sus labores, toma a veces la forma de los recorridos que hace por la ventana, permitiéndose así transitar múltiples senderos y bastas perspectivas, complaciéndose por las diferentes exploraciones que efectúa dentro del mismo trabajo. De rodillas poniendo el parquet, nuestro carpintero-poeta experimenta diversas formas de goce y disfrute 
singulares -aunque, como veremos, no solo goce-; experiencias que a su vez abren la posibilidad para que, a partir de una actitud de apertura, desplace su cuerpo del lugar que le había sido asignado y, de esta forma, se haga visible frente a él aquello que no había sido visto antes, porque no figuraba en su campo de experiencia. Esto es justo lo que sucede en uno de los viajes por la ventana, al cual, a través de su relato, el mismo Gauny nos invita a pasar:

Con un golpe de vista circular ha contemplado todo, los monumentos y las prisiones, la ciudad del tumulto y sus bastiones, las matas de follaje más allá de las barreras y las nubes osadas en los cielos infinitos. Se vuelve a poner a trabajar pero, mejor que un espejo, su alma refleja los actos de afuera, pues atraviesa los muros; percibe las abominaciones que ocultan. Los prisioneros en sus sofocantes celdas y los mercenarios que las manufacturas corroen le ocasionan cóleras humanitarias donde su indignación, acusando a la sociedad, hace que olvide los esplendores del espacio para sufrir con el mal que ha visto. (Rancière, 2010, pp. 124-125)

En este relato observamos que en su recorrido aparecen dos figuras que introducen un desajuste o conmoción y, en ese sentido, una capacidad de dividir y expropiar al mismo Gauny. Aparecen la prisión y la manufactura. Sin embargo, ese aparecer no es una experiencia habitual o corriente, sino una irrupción, una experiencia atípica que interpela a Gauny, pues, como él nos lo dice, ensombrece los esplendores de esa vida otra que ha emprendido, haciendo emerger en él una forma otra de sentir: el sufrimiento con el mal que ha visto. Es justo en este momento donde podemos ver que empieza a emerger esa forma otra de ser-en-común.

Parecería extraño pensar que la aparición de las dos sombras, que ni siquiera son dos personas o seres concretos, pudiera considerarse como una forma de seren-común. Parecería extraño porque, de hecho, Gauny está solo, no está con los otros, no está con los prisioneros ni con los trabajadores de las fábricas que él llama mercenarios; en últimas, no está en comunidad. No obstante, es ese no estar en comunidad aquello que le permite a Gauny construir una forma otra de ser-encomún. De la mano de la narración de nuestro carpintero-poeta, en lo que sigue profundizaremos en esto.

En las siguientes líneas de su relato, Gauny nos cuenta que después de la mencionada aparición irruptiva, él trata de retomar su trabajo poniendo el parquet; sin embargo, este es un intento fallido, ya que el reflejo en su interior de las 
abominaciones que los muros ocultan -a saber, los prisioneros de la celda y la manufactura- le impide continuar con su tarea:

El libre trabajador ya no puede, pues, desprender su mirada de esas dos sombras en el horizonte de su imperio: la fábrica donde sufren los mercenarios, privados de los medios o de la fuerza para emanciparse; la prisión que encierra a quienes se han perdido en los caminos de la libertad. (Rancière, 2010, p. 125)

Dicha aparición no solo irrumpe su recorrido por la ventana sino también su trabajo. No obstante, tal y como permite ver Gauny en su relato, dicho carácter irruptivo de la aparición no es absoluto, es decir, no es una implosión de la experiencia, que deja a Gauny en el abismo del sin sentido y ante la imposibilidad de cualquier figuración. A partir de esa irrupción, Gauny fija su atención en aquel lugar "que tiene como razón de ser la privación de la libertad y encierra, por principio, a quienes han querido liberarse de la disciplina común" (Rancière, 2010, p.125), esto es, el centro penitenciario. Gauny

quiere saber lo que hay tras los muros que ennegrecen su horizonte. Su curiosidad toma las dimensiones de una idea fija, ronda las inmediaciones de una de las prisiones modelos -La Roquete sin duda- y se instala en el lugar habitual de sus transacciones con los agentes del viejo mundo, a la hora en que éstos están más dispuestos a la trampa de su corrupción, la de la comida. (Rancière, 2010, p. 125)

Así pues, nuestro carpintero-poeta emprende una cierta figuración de una escena donde compartirá con dos obreros un breve recorrido por los compartimentos de lo que él mismo llama inmenso sepulcro:

Uno expresa su deseo de conocer el nuevo sistema de detención; el otro, encuadrándose en la vanidad de su poder, se le adelanta y le ofrece conducirlo al interior de la prisión como nuevo contratado. Uno quería volver su complacencia beneficiosa a su apetito, pero no sabía cómo declarar su especulación de una forma aceptable; el otro, adivinando el sentido, morigerará el aprieto del materialista, invitándole a comer luego de la dolorosa exploración, lo que fue aceptado. Entonces entraron en los compartimentos del inmenso sepulcro. (Rancière, 2010, p. 126)

Estas palabras nos permiten pensar que aquella aparición irruptiva, más que tratarse de una implosión estética, produce un reagenciamiento de signos a partir del cual Gauny teje puentes entre aquellos que construyen la prisión; puentes 
para ser-estar-con-otros; puentes que no se dan en la continuidad sino en una cierta ficcionalidad del contacto que "no se trata de una borradura de lo sensible, sino de la multiplicación y del cruce de los poderes de producción de lo sensible" (Rancière, 2008, p. 78). En otras palabras, no es simplemente olvidar aquello que desde un registro podría llamarse lo real en contraposición con lo que se llamaría ficcional -pues esta misma dicotomía quedaría desarticulada o despotencializada en virtud de los movimientos que se efectúan en dicha escena-, sino de producir una redistribución de lo que se toma en cuenta, es decir, aquello que desde un registro no era visto -en este caso no solamente la prisión celular sino, como veremos más adelante, la forma en la que los cautivos habitan en ella- y, en ese sentido, multiplicar aquello que aparece frente a nosotros. El relato de Gauny, que se sigue a esa experiencia con los obreros de la prisión, nos permite ver cómo este carpintero efectúa una y otra vez un ejercicio de multiplicación de aquello que se presenta como experienciable, es decir, multiplica aquello que él ve, oye y siente, al mismo tiempo que lo singulariza.

Durante el recorrido que Gauny emprende por la prisión, visita algunos tormentos que se despliegan en el centro penitencial; medios de tortura ya conocidos por él a partir de su experiencia de trabajo en la fábrica, pero que se ven recrudecidos en esas tumbas penitenciarias, toda vez que se hace imposible escapar de ellos. En el recorrido, nuestro destajista observa que la arquitectura de la prisión efectúa un triple suplicio sobre los prisioneros quienes, en cierta forma, aparecen sin aparecer, manifestándose en como espectros ya que, como veremos, estos emergen tácitamente en sus reflexiones.

La primera forma, a través de la cual la arquitectura funge como martirio sobre los condenados espectrales, radica en los materiales y disposición de la misma celda:

Las piedras son elegidas de entre las mejores y minuciosamente emparejadas; su ensambles se realizan con la más rigurosa adherencia [...] Precauciones inauditas son tomadas para prevenir la evasión. El camino de ronda tiene la albardilla y los ángulos exteriores de sus muros redondeados a fin de que la mano más nerviosa no pueda engancharse allí. Rejas, puertas, luces, miradas iscarióticas, perspectivas radiantes amenazan, delatan, se alinean y acechan a los secuestrados. (Rancière, 2010, p. 127)

Los condenados se vuelven rehenes de los muros, de esa arquitectura sin sombras "donde ninguna complicidad se intercambia o se adquiere, donde 
ningún azar permite el goce -incluso vano- de la esperanza: mundo sin fisuras, sin intersticios por donde la libertad o simplemente su sueño pueda pasar" (Rancière, 2010, p. 127); son rehenes de esa construcción que cobra vida como un enorme atosigador, gris, aplastante y asfixiante.

La disposición de cada piedra, esquina, luz, entre otros, es justamente la que llevará a la segunda forma de suplicio reconocida por Gauny, a saber, "la imposibilidad de que una palabra halle una respuesta, o incluso un eco" (Rancière, 2010, p. 126). En efecto, no hay

Ninguna fisura en los muros, nada se filtra, todo se pierde. Uno siente allí que la pulcritud y la regularidad son mortales; [...] se anda sin ocasionar ecos; ante los carceleros las cosas dan signos de callarse y ordenan sufrir [...] el oxígeno exterior [...] es hipócritamente reemplazado por una toma de aire que, en la disposición de su conducto, pierde la voz del detenido si intenta una comunicación a través de su orificio. La letrina que cada celda posee está también construida con este método de ensordecimiento que entierra la voz y la vida sin matarlas. (Rancière, 2010, p. 126)

Finalmente, la tercera forma de martirio ejercida a través de la arquitectura se da a partir de la disposición panóptica que, como Gauny observa, más que el direccionamiento de los comportamientos de los condenados, efectúa una tortura sobre ellos a través de ese ojo vigilante; ese ojo ciego y vidente que:

Hurga de improviso las acciones del detenido que, convulsionado por el tedio y la inquietud, se siente enroscado por la cadena de esa mirada aborreci$\mathrm{da}$ [...] en la noche un farol de gas alumbra al condenado que, turbado en su sueño por esta llama de suplicio, maldice aún más su destino y, sin poder aclimatarse a su infierno, recorre su alojamiento con la mirada temiendo encontrar el ojo traidor del carcelero que se mueve en el orificio de la puerta. (Rancière, 2010, p. 127)

A partir del recorrido exploratorio de nuestro carpintero, podemos pensar que la multiplicación estética -es decir, de aquello que se presenta como experienciable- emerge interpelándolo de una forma particular. En efecto, Gauny efectúa "otra manera de construir la relación de lo uno -o de un reducido número- al gran número [y de esta forma se consigue] singularizar aquello que el sistema confunde en una masa confusa, dotar de nuevos poderes a lo singular para figurar al gran número" (Rancière, 2010, p. 127). 
Gauny, al poner de manifiesto los tormentos de la prisión, por un lado pone de presente a los prisioneros que en ellas habitan -de una suerte de espectros que tienen la capacidad de interpelarlo- y de esta forma singulariza su cautiverio haciendo audible, pensable y experienciable los horrores que en este se vive. En otras palabras, a través del relato de Gauny, podemos apreciar que aquellos suplicios singulares dispuestos por la arquitectura, son justamente singulares porque los sufren prisioneros anónimos que a su vez también son singulares. Prisioneros que están sin estar en el relato y que configuran una forma otra de sentir para nuestro destajista pues, tal y como él mismo lo evoca con sus palabras, él sufre con ellos los suplicios y horrores de la prisión; siente en-con-junto-por esos singulares y anónimos prisioneros.

A partir de esto podríamos preguntarnos si la experiencia de Gauny no evoca aquellas que se derivan de un ejercicio de lo que llamamos compasión. Sin embargo, y siguiendo las palabras del carpintero-poeta, ese abrirse a lo que parece ser una capacidad de sentir con-los-otros, no aflora como un sentimiento de lástima, vertical y en último término incapacitante por los desdichados prisioneros -similar al que puede aflorar en aquellos discursos de las asociaciones o de los sansimonianos, en los que hacen despertar la piedad a través de presentar la desgracia de los otros-; tampoco parece asemejarse a esa compasión que desde el utilitarismo se defiende y que nace de la igual potencia de padecer dolor y placer. Por el contrario, ese sentir-con los otros supone otro tipo de experiencias además del dolor, que parecen surgir al reconocerse junto a esos prisioneros como poseedor de una igual capacidad.

Gauny y aquellos secuestrados aparecen en la escena, además como sufrientes de los suplicios penitenciarios, como seres que maldicen su destino, convulsionan por el tedio y la inquietud, se sienten enroscados por la cadena de ese ojo hurgador; en breve: no se aclimatan a ese infierno porque saben que es un infierno. Así, los prisioneros emergen como aquellos que saben que "cada cimiento [dispuesto por sus propios hermanos] es un ultraje a la humanidad, un peso más que arrojan sobre la sordera de su conciencia” (Rancière, 2010, p. 128); aparecen como aquellos que saben que:

La desigualdad de las condiciones, el desempleo de largo término, la repugnancia que inspira un trabajo sobreexplotado o contra nuestros gustos, la ausencia de educación, una exacción, una comparación, un vértigo hacen 
combatir en ocasiones a los más débiles y los más fuertes de la plebe contra la sociedad que los deshereda en el vientre de su madre y les prohíbe vivir según el empleo integral de sus facultades. (Rancière, 2010, p. 128)

En esa medida, ese sentir-con-otros no se traduce solamente en reconocer una igual capacidad de sentir dolor, sino también en una situación que podríamos llamar de conocimiento. Gauny junto-con-por los prisioneros, aún sin poseer la ciencia de los filósofos que desentrañan los secretos de la explotación y la desigualdad, conocían esos secretos; más aún, dicho conocimiento no se afincaba para reafirmar una identidad de ser prisionero como delincuente y perturbador del orden establecido, perteneciente a una raza de obreros condenados a las libaciones de la inferioridad de su raza y a la repetición del círculo de la dominación a la que los subyugaban otra clase y sus mismos apetitos; viciosos que las encuestas sobre los trabajadores de los Archivos Cabet (Rancière, 2010, p. 319) no dudarán en identificar como "sujetos entregados a las sensualidades conocidas: ebriedad, tabernas, café, juegos, bailes, merenderos, disipación, carnaval” (Rancière, 2010, p, 319). Ese conocimiento se constituye más bien como una especie de dispositivo de ruptura con respecto a la identidad que les había sido asignada. Ruptura justamente que parece emerger de lo que Bassas Vila (2011) advierte como la apropiación "de lo otro, de aquello otro que les había sido denegado: por una parte, la capacidad de hablar [...], por otra parte, la capacidad de pensar" (p. 7).

Aquella situación que suscita un conocimiento inesperado y que se constituye como un dispositivo que erosiona la identidad impuesta, hace emerger a Gauny junto-con-por los prisioneros no como seres expulsados "a la noche del silencio o el ruido animal de las voces que expresan agrado o sufrimiento" (Rancière, 1996, p. 36), sino como poseedores de logos dentro de la antigua dicotomía de "aquellos de quienes hay un logos - una palabra conmemorativa, la cuenta en que se los tiene- $y$ aquellos de quienes no hay un logos, quienes hablan verdaderamente y aquellos cuya voz para expresar placer y pena, solo imita la voz articulada" (Rancière, 1996, p. 37). Así, Gauny junto-con-por los secuestrados aparecen como partícipes de un poder que no es reconocido por todos y, en esa medida, ponen en cuestión las fronteras que distribuyen jerárquicamente la posesión del logos.

Sin embargo, cuando afirmamos que los prisioneros junto a Gauny emergen como poseedores de logos, no se presentan como unos seres con igual capacidad para articular discursos; tampoco como animales poseedores de una capacidad 
que marca la pauta para privilegiar unas formas de vida sobre otras. Lo que esta escena sugiere es justamente poner en duda las fronteras entre palabra y ruido, es decir, cuestiona el criterio que hizo que esa palabra fuera ruido - que no es lo mismo que plantear que el ruido luego se incluya como palabra-; fronteras que al ser cuestionadas, desajustan la cuenta dada y permiten la emergencia de una comunidad otra entre Gauny y los prisioneros.

En efecto, el reagenciamiento de los signos de la escena figurada permite reconfigurar aquello que se constituía como lo común, toda vez que pone en suspenso la experiencia de lo colectivo que asigna a cada quien su lugar y parte en el cuerpo social; en breve, se efectúa una cierta resignificación de lo que es el cuerpo social dado. En ese sentido, a través de la experiencia de Gauny hay una verificación de la igualdad de la que Rancière habla en diferentes pasajes de sus obras $(2006,1996,2003)$. Igualdad reconocida como un cierto universal que existe o produce sentido justamente en lo singular, que no es un valor que se invoque (Rancière, 2006, pp. 17-26), ni tampoco una capacidad "decretada por la ley o por la fuerza [...] recibida pasivamente, sino [como] una igualdad en acto, comprobada a cada paso" (Rancière, 2003, p. 103); es decir, como un principio vacío que Gauny justamente comprueba, significa y singulariza con su experiencia. Efectivamente, la verificación de la igualdad que se efectúa a través de dicha escena no es la afirmación de una verdad, sino que se da a partir del quiebre de identidades que lleva a figurar y a hacer perceptible la igualdad de aquellos prisioneros en la participación del logos al que nos referimos atrás; la comprueba, la hace vida, la hace perceptible. De esta forma, se tejen puentes con los otros, un tejido inédito, es decir, una forma otra de ser-en-común, que mueve una forma de sentir otra y una forma de percibir otra.

Teniendo presente que esta forma otra de ser-en-común ha emergido de una cierta interrupción, cabe añadir que dicha experiencia no se trata de un instante efímero de un flujo temporal que luego vuelve a normalizarse, sino que se convierte en una suerte de "mutaciones efectivas" de la distribución de lo sensible, que en el caso de Gauny desplegará aún otra forma de ser-en-común, difernte a aquella de la prisión. Como señalamos más arriba, a partir de esa experiencia en la prisión ocurre una reconfiguración del sensorium común, esto es, de lo decible, audible y pensable como común. Esta reconfiguración no dejará a nuestro destajista igual que antes de dicha experiencia, por eso Rancière señala que de no 
haber fijado su mirada en la prisión, nuestro carpintero-poeta hubiera ahondado en la "razón apropiada para el goce de lo máximo que permite la relación presente de la libertad con la esclavitud" (Rancière, 2010, p. 161). Después de esta experiencia, Gauny irá "de individuo en individuo a expandir su alma" y de esta forma, a unirse más a la humanidad, pues dando y recibiendo se une "a la raza más que a la persona, [y así] llega a alcanzar una gran apreciación de la felicidad” (Rancière, p. 161). En otras palabras, nuestro destajista, como él mismo lo reconoce-luego Rancière se sumará a ese reconocimiento-, al fijarse en la idea de la prisión, se transforma de tal manera que dicha experiencia lo lleva a asemejarse a la figura del Bautista, aquel hombre del desierto "que reúne en su meditación los dolores y las esperanzas de la humanidad"; aquel hombre que implica "el desencadenamiento de la humanidad”. Un ser del desierto que está más allá del equilibrio del entendimiento rectificado:

Un espíritu en revuelta, en el sentido más inmediato del término: imaginación abismada en 'uniones de Dios, de la naturaleza y de los seres', en la que [...] se pierde un poco muy a menudo; pero también una imaginación 'alienada en el sufrimiento', que reúne en su meditación los dolores y las esperanzas de la humanidad. (Rancière, 2010, p. 162)

Esta reconfiguración del sensorium y esa forma de ser-en-común que emerge en la experiencia de la prisión, abre la puerta a una forma otra -aún otra- de seren-común, que tomará la figura de un viaje, aquel de una amistad otra: "resonancia de lo mismo con lo mismo, abierta en la conspiración universal de las armonías más bien que complementariedad de las cualidades y de los servicios afectados a cada sexo" (Rancière, 2010, p. 154). Como dijimos, Gauny irá de individuo en individuo desplegando y extendiendo su alma y, de esta forma, se asemeja a la figura del Bautista; sin embargo, ese viaje de individuo a individuo, es un viaje de "amistad tanto más viva y contagiosa cuanto que no es nunca un encuentro de paso" (Rancière, 2010, p. 161). Esa amistad que se despliega en sus viajes será de hecho una extraña amistad hacia una "masa susceptible de inflamarse en la misma medida en que ella no es una concentración de familias, de cuerpos, de clases o de corporaciones, sino una pura colección de individuos sensibles [...] con [los] cuales la revuelta entabla una relación puntual y sin reciprocidad" (Rancière, 2010, p. 160). En ese sentido, será una amistad singular y al mismo tiempo universal toda vez que, y aunque se de de individuo a individuo, está exenta de 
particularismos: una relación con todos y con nadie en específico. Así, esa extraña amistad no será tampoco aquella de una asimilación del otro; no es una identificación con o apropiación del otro, sino como una amistad otra que no busca saturar la relación entre cuerpo y cuerpo.

Ahora bien, debido a que dicha amistad no emergerá hacia una persona en particular, este tipo de relación no buscará concretarse en una comunidad de la continuidad de los cuerpos sino más bien como la unión en la separación. En efecto, la amistad que parece desplegar nuestro carpintero será una fuerza que se despliega y no retiene; como una potencia que no teme darse, regarse, que se regala siempre y no quiere apropiar al otro en un movimiento autoafirmativo; en resumen: una circulación libre de los afectos. Es por esto que la fuerza imprevisible de esos extraños amigos "viene de que no aplican la directiva de ningún centro y que cada uno ignora lo que el otro hace" (Rancière, 2010, p. 163). El viaje de amistad que trae esta circulación de los afectos, como ya lo advertimos más arriba, hará emerger otra comunidad diferente a aquella de la prisión; una paradójica o mejor aún, una inédita forma otra de ser-en-común, que no es agregativa ni se da en la continuidad sino más bien en la distancia; comunidad otra conformada en los espaciamientos:

Por esos hombres que ya han renunciado a todos los beneficios e interiorizado todas las negaciones del mundo de la explotación, que viven ya el no ser de este mundo: el zapatero remendón cuya camisa ordinaria no fue hecha con la explotación de ningún asalariado y cuyo espíritu se las ingenia para encontrar lo inconmensurable en lo infinitamente pequeño; el carretero que ha levantado con sus propias manos su casita cuyos muros mal terminados alimentan en el exterior diversas vegetaciones y están cubiertos en el interior con planos y figuras geométricas cuyas líneas parecen proyectarse hacia lo imposible, y que -mientras sueña en sondear las profundidades de la tierra y en hallar la realización del movimiento perpetuo- inventa sistemas de tracción para aligerar el esfuerzo de los caballos y frenar la rapidez excesiva de los ricos equipajes; [...] el afilador de barrio quien ha racionalizado su "imposesión" para hacerse una propiedad de todo lo que no tiene. (Rancière, 2010, p. 163)

Esta forma de comunidad, o mejor, esta forma de ser-en-común escaparía a la lógica de la propiedad -tan problemática y problematizada en el siglo 
pasado $^{8}$ - que no apela a una esencia a partir de la cual predicar la pertenencia o no de la comunidad. Así mismo, no deja en la inactividad total sino que permite la figuración de tal forma que lleva al despliegue de la acción.

\section{Breves consideraciones finales o cuestiones abiertas}

El movimiento De figuRAS que se efectúa a través de La noche de los proletarios permite atender a una experiencia de otro tipo de comunidad, que no se da en la continuidad de los cuerpos sino en los espaciamientos. Desde esta perspectiva, podríamos pensar que ese tipo de hallazgos mueven consideraciones éticas, en la medida en que apelan a la forma en la que construimos relaciones unos con otros. Una experiencia ética que en lugar de hablarnos de normas, moldes por seguir o de un deber ser universalmente vinculante, nos habla de una cierta actitud de apertura que permite posibilidades de alteración o transformación y alteración de sí y de los otros. Una experiencia ética, a pesar de lo dicho por Rancière respecto de esta expresión pues para él la ética -entendida como ethos- es el pensamiento que establece la identidad entre un entorno, una manera de ser y un principio de acción, que parece poder funcionar en una lógica en donde "el suplemento, a diferencia de la comunidad política, no tiene lugar de ser porque todo está incluido" (Rancière, 2005, p. 29).

Con todo, no pretendemos afirmar que existe un interés ético soterrado en la obra de Rancière, ni que su interés sea ético y no político. El ejercicio desplegado en las anteriores páginas permite preguntarnos por el significado de estas experiencias de La noche de los proletarios a la luz de las afirmaciones de Rancière respecto de la política, toda vez que las experiencias de subjetivación política como las que se abordan en obras tales como El desacuerdo, parecen emerger en un registro diferente a aquellas analizadas en este escrito. Queda así abierta la cuestión sobre la relación entre aquello que Rancière ha formulado en otras partes de su obra respecto a la subjetivación política y el registro que emerge en $\mathrm{La}$ noche de los proletarios.

Así mismo, cabría explorar las diferencias entre las experiencias de la verificación de la capacidad de cualquiera con cualquiera que se despliegan en $L a$

Sobre la lógica de la propiedad, véase: Esposito, 2010. 
noche de los proletarios y aquellas de El desacuerdo y otros textos que abordan explícitamente la cuestión de la subjetivación política. Si bien las voces de La noche de los proletarios y las de El desacuerdo nos hablan de "la capacidad de cualquiera y lo que es el ejercicio de una capacidad, la manera como se define y se ejerce" (Rancière, 2011, p.184. Las cursivas son mías), no obstante, esta capacidad se hace valer de modos diferentes en las obras mencionadas. En efecto, cuando "se concreta bajo formas colectivas" como en el caso del Aventino", recogido en $E l$ desacuerdo, emerge "un" nosotros que es político porque "la política tiene esto de específico: que apela a formas de enunciación colectiva” (Rancière, 2011, p. 184); caso diferente de la verificación movilizada en Gauny y analizada en este escrito. La elaboración de la respuesta queda abierta para futuros ejercicios.

Finalmente y además del interés teórico que este tipo de lecturas pueda suscitar, creemos que pensar la comunidad en los términos que nos sugiere Gauny a través de Rancière, puede, en cierta forma, renovar nuestros imaginarios moviéndonos a pensar y sentir de otro modo, e invitarnos a desplegar un ejercicio de apertura respecto de las experiencias que nos rodean y que muchas veces pasamos desapercibidas.

\section{Referencias}

Foucault, M. (2010). El coraje de la verdad. Buenos Aires: Fondo de Cultura Económica.

Gauny, L. G. (1983). Louis Gabriel Gauny, Le philosophe plébéien. Paris: Editions La Découverte.

What is 'Islamic State'? (2015, diciembre 2) BBC. Recuperado de http://www. bbc.com/news/world-middle-east-29052144

German PEGIDA movement set to start political party. (2016, julio 19). $D W$. Recuperado de http://www.dw.com/en/german-pegida-movement-set-tostart-political-party/a-19410313

9 Según el relato de Ballanche de 1829, y retomado por Rancière (1996) en El desacuerdo, en la secesión de los plebeyos en el monte Aventino acaecida hacia el 400 a.C. durante la República romana, emerge un conflicto que nos habla de una subjetivación política toda vez que ella misma es "una disputa sobre la cuestión de la palabra misma [...] [es decir] la cuestión en juego es saber si existe un escenario común en donde plebeyos y patricios puedan debatir algo" (p. 37). 
NAACP Legal History. (2009-2016). NAACP. Recueprado de http://www. naacp.org/pages/naacp-legal-history

Rancière, J. (1983). Introduction. En: L. G. Gauny, Le philosophe plébéien (pp. 5-19). Paris: Editions La Découverte.

Rancière, J. (1996). El desacuerdo. Buenos Aires: Ediciones Nueva Visión.

Rancière, J. (2003). El maestro ignorante. Barcelona: Laertes.

Rancière, J. (2005). El viraje ético de la estética y la politica. Santiago de Chile: Palinodia.

Rancière, J. (2006). Política, policía y democracia. Santiago de Chile: LOM.

Rancière, J. (2008). El teatro de imágenes. En: N. Schweizeri, Alfredo Jaar, La politica de las imágenes. Santiago de Chile: Metales Pesados.

Rancière, J. (2010). La noche de los proletarios. Buenos Aires: Tinta Limón.

Rancière, J. (2011). El tiempo de la igualdad. Barcelona: Herder.

Rancière, J.; Jeanpierre, L. \& Zabunyan, D. (2012). La méthode de l'égalité: entretien avec Laurent Jeanpierre et Dork Zabuyan. Paris: Bayard. 